\title{
Device Related Infection, CTCAE
}

National Cancer Institute

\section{Source}

National Cancer Institute. Device Related Infection, CT CAE. NCI Thesaurus. Code C143406.

A disorder characterized by an infectious process involving the use of a medical device. 